\title{
Insecticidal activity of the essential oil from fruits and seeds of Schinus terebinthifolia Raddi against African malaria vectors
}

\author{
Eliningaya J Kweka ${ }^{1,2^{*}}$, Mramba Nyindo², Franklin Mosha ${ }^{2}$ and Ary G Silva $a^{3,4}$
}

\begin{abstract}
Background: Alternative insecticides for the control of malaria and filarial vectors are of paramount need as resistance is increasing among classes of insecticides currently in use in the public health sector. In this study, mosquitocidal activity of Schinus terebinthifolia essential oil against Anopheles gambiae s.S., An. arabiensis and Culex quinquefasciatus was assessed in laboratory, semi- field and full- field conditions
\end{abstract}

Method: Twenty third instar larvae of both Anopheles gambiae s.s. and Cx. quinquefasciatus were exposed to different dosages of plant extract in both laboratory and semi- field environments. Observation of the mortality response was assessed at intervals of 12, 24, 48 and 72 hours. Adult semi- gravid female mosquitoes were exposed to papers treated with S. terebinthifolia and compared with WHO standard paper treated with alphacypermethrin (0.05\%).

Results: Gas chromatography, coupled to mass spectrometry, identified 15 compounds from S. terebinthifolia extracts, the most abundant identified compound was $\delta$-3-carene $(55.36 \%)$ and the least was $\gamma$-elemene $(0.41 \%)$. The density of the oil was found to be $0.8086 \mathrm{~g} / \mathrm{ml}$. The effective dosages in the insectary ranged from 202.15 to $2625.20 \mathrm{ppm}$ and were further evaluated in the semi- field situation. In the laboratory, the mortality of $C X$. quinquefasciatus ranged from 0.5 to $96.75 \%$ while for An. gambiae s.s it was from 13.75 to $97.91 \%$. In the semi- field experiments, the mortality rates observed varied for both species with time and concentrations. The $L C_{50}$ and $L C_{95}$ value in the laboratory was similar for both species while in the semi- field they were different for each. In wild, adult mosquitoes, the $\mathrm{KT}_{50}$ for $\mathrm{S}$. terebinthifolia was 11.29 minutes while for alphacypermethrin was 19.34 minutes. The 24 hour mortality was found to be $100.0 \%$ for S. terebinthifolia and $75.0 \%$ for alphacypermethrin which was statistically significant $(P<0.001)$.

Conclusion: The efficacy shown by essential oils of fruits and seeds of $S$. terebinthifolia has given an opportunity for further investigation of individual components of these plant extracts and to evaluate them in small- scale field trials.

\section{Background}

In Tanzania, it is estimated that $95 \%$ of Tanzanians are living in stable malaria transmission areas. About 17-20 million clinical episodes of malaria are reported per year and 80,000 of all deaths are attributed to malaria annually [1,2]. Malaria has been attributed to $40 \%$ of outpatients' attendances across health facilities in Tanzania [2]. The recent statistics in Tanzania indicate that, malaria

\footnotetext{
* Correspondence: pat.kweka@gmail.com

'Tropical Pesticides Research Institute, Division of Livestock and Human Disease Vectors Control, Mosquitoes Section, P.O.Box 3024, Arusha, Tanzania Full list of author information is available at the end of the article
}

mortality related cases have decreased from 100,000 [1] to 80,000 deaths [2].

For mosquito vector control, effective insecticides and appropriate techniques for application are highly in demand. The reduced susceptibility statuses of malaria and filarial vectors to the recommended insecticides of choice have posed an alarming situation in public health [3-5]. Both vectors and parasites of malaria have shown resistance selection pressure to insecticides and antimalarial drugs respectively [4,6-10].

Most programmes for malaria vector control rely on insecticide treated nets (ITNs), indoor residual spraying (IRS) and larval control [11-17] and treatments of

\section{Biomed Central}


diagnosed patients with drugs of choice $[8,10]$. The insecticides mainly authorized for use in malaria control programmes belong to the pyrethroid class, namely permethrin, deltamethrin, alphacypermethrin and lambdacyalothrin [18], organophosphates [19,20], carbamates $[19,21]$, and chlorophenapyr [22]. The organochloride class is currently restricted for public health vector control use, though it was effective against malaria and other disease vectors [23]. The rest of the insecticide classes have been effective when in combination rather than when applied singly [24]. The use of these synthetic pesticides have been found to have side- effects in non-targeted organisms [25].

Plant phytochemicals have more specific effects and could be usefully integrated with other control measures to design comprehensive, appropriate and effective management protocols with less collateral harm to the environment and non- target species [26]. The poor socio-economic status among individuals in malaria endemic areas has denied them access to protective tools against malaria vectors such as bed nets, IRS and topical repellents $[27,28]$. Alternative chemical compounds with multi- effects in different stages of mosquito development are needed to complement the compounds which are currently in use. Since ancient times, plant extracts have been in use due to their medicinal and vector control properties [29,30]. Currently, several plant species have shown to be effective when used against different disease vectors [31,32]. In Tanzania, a number of plant species have demonstrated major activity against malaria vectors in the laboratory [32-38] and in full field evaluations [36,37].

Schinus terebenthifolia Raddi (Anacardiaceae), commonly known as Brazilian pepper, is an evergreen tree, native to South America, in particular Brazil, Paraguay and Argentina. The fruits are drupes and are green when they are immature, and become dark pink or red, when mature [39], with one dark brown seed per fruit [40]. The essential oil of the vegetative parts has been shown to have non-steroidal anti-inflammatory activity by inhibiting phospholipase A2 [41], acting by competitive inhibition of this specific enzyme [42] due to one of its components, schinolmasticadienoic acid [43]. Its healing activity was also directly related to triterpenoids present in fruits [44]. This essential oil also showed antimicrobial activity by several substances, such as terebinthone, hydroxymasticadienoic, terebinthifolic, and ursolic acids [45], and antifungal activity was also evidenced [46]. The essential oil of fruits and seeds of S. terebinthifolia has recently shown larvicidal activity, in a dose dependent way, against third instar larvae of Stegomyia aegypti, the dengue fever vector [26]. To date, there are no reports on the use of $S$. terebinthifolia extracts against $A n$. gambiae s.s., An. arabiensis and Cx. quinquefasciatus. Botanical pesticides are preferred in comparison to synthetic pesticides, as they are eco-friendly and biodegradable [47].

Since $A n$. gambiae s.l. is mainly found in sub-Saharan Africa $[46,47]$, and S. terebinthifolia is an exclusive neotropical plant species, native of South America [37], their geographical distribution range would never overlap. However, both of these species had been anthropically put in contact after the accidental introduction of $A$. gambiae s.l. in northeastern Brazil in 1929, probably from Senegal [48]. The correct identity of the invader, if An. gambiae or An. arabiensis, is not well established, unless by a modeling proposal that points to An. gambiae [47]. Although the mosquito species is believed to have been eradicated from Brazil by the end of 1940s [49], the control efforts ended the epidemics, but low-level and localized rural transmission still persist [50].

Therefore, it was the aim of this study to investigate the biological control activity of the essential oil of $S$. terebinthifolia Raddi against An. gambiae s.s., An. arabiensis and $C x$. quinquefasciatus, as well as to assess and quantify the mosquitocidal effect in both laboratory and semifield situations. The insecticide susceptibility status of a wild population of $A n$. gambiae s.l. was evaluated using alphacypermethrin $(0.05 \%)$ as standard and S. terebinthifolia as a new product.

\section{Materials and methods}

\section{Essential oil extraction, purification, and density determination}

Fruits of the Brazilian pepper tree were collected from specimens occurring in the region of Vitória, Espírito Santo, Brazil, and $5.0 \mathrm{~kg}$ of those fruits were separated from any impurities in the Laboratory of Plant Ecology, at the Centro Universitário Vila Velha (UVV), and afterwards they were crushed. From that amount, $1.2 \mathrm{~kg}$ of crushed fruits and seeds were divided into 12 samples of $100 \mathrm{~g}$, which were extracted for determination of the mean yield and the mean density. The remnant $3.8 \mathrm{~kg}$ were also crushed and extracted at a larger scale to produce essential oil for biological assays.

The extraction was made by hydrodistillation in a Clevenger apparatus with the crushed fruits and seeds, during one hour of the extraction process. After extraction, the essential oil was transferred to a glass vial, and its purification was made by separation of the remnant water by freezing, and the essential oil which was kept in liquid phase, was drained from the vial [48].

Both the mean yield and the mean density were gravimetrically determined. For the mean yield, the essential oil produced by each sample of $100 \mathrm{~g}$ crushed fruits and seeds were weighed, and the mean density was determined by weighing $1 \mathrm{~mL}$ of liquid, in an acclimatized room at $20^{\circ} \mathrm{C}$, on an analytical balance with accuracy of $1.0 \mathrm{mg}$. After extraction, 12 samples of $100.0 \mathrm{~g}$ of crushed 
fruits and seeds were taken as replicates. All of these procedures were performed in the laboratory of Chemical Sciences, UVV.

\section{Chromatographic Analysis}

The identification of the essential oil components was carried out by high resolution gas chromatography analysis, in the Fine Chemistry Laboratory, at Tommasi Analítica. The injection volume was $2 \mu \mathrm{L}$, composed of $1.6 \mathrm{~mL}$ of a solution of essential oil $(30 \mathrm{mg} / \mathrm{ml})$ and $0.4 \mathrm{~mL}$ of a solution of hydrocarbon series of $\mathrm{C}_{7}-\mathrm{C}_{30}$, as internal standard, both in $n$-hexane as solvent.

The gas chromatography coupled with mass spectrometry - GC-MS - system used consisted of a gas chromatograph, Thermo Scientific ${ }^{\circledR}$ Ultra GC coupled to a mass spectrometer, Thermo Scientific ${ }^{\circledR}$. The fused silica capillary column used was a DB-5 J \& W Scientific (30 m $\times$ $0.25 \mathrm{~mm} \times 0.25 \mathrm{~mm})$. Helium was the carrier gas and the column temperature program was increased by $3^{\circ} \mathrm{C}$ per minute between $60^{\circ}-240^{\circ} \mathrm{C}$. The mass spectra were obtained at $70 \mathrm{eV}$ at a scan rate of $0.84 \mathrm{scan} / \mathrm{sec}$, at the range $\mathrm{m} / \mathrm{z} 40-500$. The retention times of sample components and a mixture of $n$-alkanes from $C_{7}-C_{30}$, co-injected into the GC-MS system under the same temperature program were used for the calculation of the Arithmetic Retention Index - AI - and the Kovats Retention Index (KI) [47]. Identification of components was based on several methods: the calculated AI and KI and mass spectra. The AI and KI were compared with the ones in the available literature [49], and the mass spectra, compared with the GC-MS spectral library.

\section{Essential oil dispersion at different concentration}

Dimethyl sulfoxide (DMSO) was used as surfactant in making the solutions as the dispensing medium for the essential oil and exposure of larvae to treatment. The parts per million (ppm) was counted as the weight of the final solution made. Mixing $1 \mathrm{~mL}$ of the essential oil with $5 \mathrm{~mL}$ of DMSO $(\mathrm{d}=1.1004 \mathrm{~g} / \mathrm{mL})$ plus the weight of $994 \mathrm{~mL}$ of water, that was $(0.822 \mathrm{~g}+5.502 \mathrm{~g}+994 \mathrm{~g}=1000.344 \mathrm{~g})$. This final weight of a litre of solution thereafter was converted to ppm which was $((0.822 * 1000) / 1000.344)$. Therefore for a litre of solution this gave $822 \mathrm{ppm}$. Stock solution was prepared from the essential oil extracted to make a solution of $2465.20 \mathrm{ppm}$ in three litres of water, which was serially diluted to get the lowest concentrations for experiments. The lowest concentration screened against larvae was 80.86 while highest was 2465.20 ppm.

\section{Larvae bioassays in the laboratory}

A series of bowls (diameter $14 \mathrm{~cm}$, depth $10 \mathrm{~cm}$ ) was prepared in five replicates for each control, blank and treatment performed, and each replicate received 20 larvae, including a control with distilled water, and a blank control with an aqueous solution of $0.50 \%$ of DMSO that was used as dispersing medium for the essential oil and exposure of larvae to treatment. The number of serial dilutions that were made to assay for the dosages that were effective to cause mortality were as described in WHO larvae bioassay protocol [50]. Serial dilutions were made from $80.86 \mathrm{ppm}$ to $2465.20 \mathrm{ppm}$. The range of doses with a mortality effect were selected and considered for the laboratory bioassays. Mortality recordings were taken at $12,24,48$, and 72 hours for both treatments and control. The dead and moribund larvae were recorded as dead.

\section{Larval bioassay in the semi- field}

Semi- field environment structures used in this study were similar to those described in previous studies [51]. The semi- field evaluation protocol was adopted from the WHO protocol [50]. Similar dosages used in the laboratory were evaluated in the semi- field. A series of bowls (with diameter of $14 \mathrm{~cm}$ and depth $10 \mathrm{~cm}$ ) was prepared in five replicates for each control, blank and treatment performed, and each replicate received 20 larvae, including a control with distilled water, and a blank control with an aqueous solution of $0.50 \%$ of DMSO that was used as dispersing medium for the essential oil and exposure of larvae to treatment. Other procedures were performed similar to the larval bioassays in the laboratory.

\section{Hatchability effect of the essential oil of S. terebinthifolia on eggs of An. gambiae s.s. and Cx. quinquefasciatus} Hatchability is defined as the proportion of eggs hatched in treatment or control to the number of eggs introduced initially. Overnight laid eggs of An. gambiae s.s. and Cx. quinquefasciatus were introduced in treatments and controls, and then monitored for 3 consecutive days. Twenty eggs of An. gambiae s.s. and one egg raft of $C x$. quinquefasciatus were submerged in water treated with three selected essential oil concentrations (808.6, 1617.2, $2465.20 \mathrm{ppm}$ ) separately and compared with untreated dechlorinated water. First instar larvae were counted and picked- up every morning in both control and treatments for the all observations.

\section{Adult susceptibility test for wild population of $A n$. gambiae s.I}

Whatman square size filter paper (Ahlstrom Filter Paper, Grade 222, catalogue number 2228-1416) was impregnated with the dispersion of the essential oil using a micropipette at a concentration of $2021.5 \mathrm{ppm}$. After impregnation, filter papers were treated and laid on clean table to dry in a dark room for $24 \mathrm{~h}$ before experiments. These papers were compared with the WHO standard impregnated paper, alphacypermethrin, 0.05\% (Batch No. AL083; Control No. 083, Impregnated, June 2010 and 
expires June 2011). Adult wild female mosquitoes were aspirated from a cowshed and held for 24 hours for blood fed mosquitoes to become semi- gravid before experiments. The susceptibility test was carried out as described in WHO insecticide susceptibility test protocols $[52,53]$.

\section{Data Analyses}

The percentage mortality observed was corrected by Abbott's formula [54]. Analysis of variance (ANOVA) was performed to calculate the mean mortality and standard error in different hours for each concentration for third instar larvae. Chi-square test was used to calculate the statistical difference between the proportions of eggs of $C x$. quinquefasciatus and An. gambiae s.s. hatched for each dosage used and in mortality and knockdown differences for susceptibility test between $S$. teberinthifolia and alphacypermenthrin.

The mortality proportions of An. gambiae s.s. and $C x$. quinquefasciatus in treatments and controls were compared using the Chi- square test. Statistical analysis of the experimental data was performed using PWAS statistics 18.0 (Version 18.0 for Windows, SPSS Inc., Chicago, IL) and MS EXCEL 2003 to find out the knockdown time for $50 \%\left(\mathrm{KT}_{50}\right)$, mean and $95 \%$ confidence intervals.

\section{Results}

\section{Essential oil extraction purification and density} determination

After purification $110.37 \mathrm{~mL}$ of essential oil were obtained, with a density of $0.8086 \pm 0.0010 \mathrm{~g} \mathrm{~mL}^{-1}$, representing $2.73 \pm 0.25 \%$ yield from fresh fruits.

\section{Chromatographic Analysis}

The separation of the essential oil components revealed that the chromatographic profile (Figure 1) was composed of 56 substances, mainly mono- and sesquiterpenoids, and among them, only three substances, the monoterpenoids $\delta$-3-carene (55.36\%), $\alpha$-pinene $(15.62 \%)$, and sylvestrene (10.69\%) corresponded to $81.67 \%$ of the total composition of the essential oil (Table 1). When 12 more substances are added to the previous ones, a total of $96.11 \%$ of the essential oil composition is revealed, including sesquiterpenoids and phenylpropanoids, besides the already cited monoterpenoids. Among those minor compounds that comprised $14.44 \%$ of the essential oil composition are germacrene $D, \beta$-patchoulene, myrcene, eugenol, terpinolene, sativene, $\beta$-cedrene, cis- $\alpha$-santalol, cis-muurola-3,5-diene, hedycaryol, $\delta$-elemene, $\gamma$-elemene. The other 41 compounds occurred in residual traces and comprised only $3.89 \%$ of total composition.

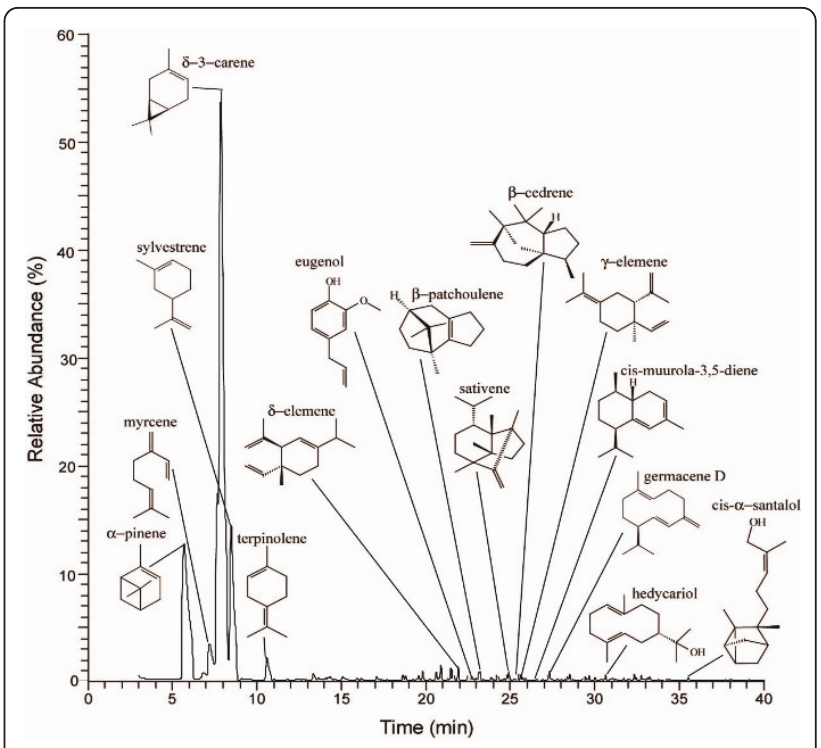

Figure 1 Chromatographic profile and chemical structure of major constituents of the essential oil from fruits and seeds of Schinus terebinthifolia.

\section{Larval bioassays in the laboratory}

From the range of doses used, the mortality effect observed was from $202.15 \mathrm{ppm}$ to $2625.20 \mathrm{ppm}$ in dechlorinated water. After 72 hours, the mean mortality percentage ranged from 0.5 to $96.75 \%$ for $C x$. quinquefasciatus and 13.75 to $97.91 \%$ for An. gambiae s.s (Table $2)$. The interval observations (12, 24, 48, and 72 hours) in each concentration among laboratory experiments had mortality responses that varied with time (Table 2). Overall mortality responses between An. gambiae s.s. and $C x$. quinquefasciatus were statistically significantly different in all doses with more An. gambiae s.s. larvae dying $\left(\chi^{2}=12.40, P \leq 0.0001\right)$. The $\mathrm{LC}_{50}(\mathrm{ppm})$ in laboratory was similar for both An. gambiae and $C x$. quinquefasciatus 1288.71 (1004.20 - 1573.21).

\section{Larvae bioassay in the semi- field}

The mortality trends observed in the laboratory assays were similar in semi field experiments for both $C x$. quinquefasciatus and An. gambiae s.s. (Table 2). The interval observations (12, 24, 48, and 72 hours) in each concentration among semi- field experiments had mortality responses that varied with time (Table 3). Mortality of An. gambiae s.s. larvae was significantly more than that of $C x$. quinquefasciatus $\left(\chi^{2}=19.27, P \leq 0.0001\right)$. In semi- field experiments, the overall 72 hour mortality response of $C x$. quinquefasciatus and An. gambiae s.s. in two lower doses $(202.15,404.3)$ was observed to be higher than observed in laboratory for the same species. In the semi- field, $\mathrm{LC}_{50}(\mathrm{ppm})$ for An. gambiae s.s. was 
Table 1 Major constituents of essential oil from fruits of Schinus terebinthifolia Raddi, determined by gas chromatography coupled to mass spectrometry and by comparison of their Artihtmetic and Kovats Retention Indices

\begin{tabular}{|c|c|c|c|c|c|}
\hline \multicolumn{2}{|c|}{ Arithmetic Index } & \multicolumn{2}{|c|}{ Kovats Index } & \multirow[b]{2}{*}{ Substance } & \multirow[b]{2}{*}{ (\%) } \\
\hline Calculated & Adams, 2009 & Calculated & Adams, 2009 & & \\
\hline 1010 & 1008 & 1011 & 1011 & $\delta$-3-carene & 55.36 \\
\hline 933 & 932 & 938 & 939 & $\alpha$-pinene & 15.62 \\
\hline 1027 & 1025 & 1031 & 1030 & sylvestrene & 10.69 \\
\hline 1479 & 1480 & 1481 & 1481 & germacrene D & 2.48 \\
\hline 1377 & 1379 & 1379 & 1381 & $\beta$-patchoulene & 1.99 \\
\hline 988 & 988 & 990 & 990 & myrcene & 1.89 \\
\hline 1355 & 1356 & 1357 & 1359 & eugenol & 1.71 \\
\hline 1087 & 1086 & 1089 & 1088 & terpinolene & 1.52 \\
\hline 1392 & 1390 & 1393 & 1391 & sativene & 0.93 \\
\hline 1418 & 1419 & 1419 & 1420 & $\beta$-cedrene & 0.89 \\
\hline 1675 & 1674 & 1676 & 1675 & cis- $\alpha$-santalol & 0.77 \\
\hline 1447 & 1448 & 1449 & 1450 & cis-muurola-3,5-diene & 0.76 \\
\hline 1546 & 1546 & 1548 & 1548 & hedycaryol & 0.66 \\
\hline 1336 & 1335 & 1339 & 1338 & $\delta$-elemene & 0.44 \\
\hline 1434 & 1434 & 1436 & 1436 & $\gamma$-elemene & 0.41 \\
\hline \multicolumn{5}{|c|}{ Total } & 96.11 \\
\hline
\end{tabular}

847.37 [726.24 - 968.50] while for Cx. quinquefasciatus it was 829.88 [719.97 - 939.79].

\section{Hatchability effect of S. terebinthifolia on eggs of An. gambiae s.s. and $C_{x}$. quinquefasciatus}

Hatchability rate was significantly concentration dependent; hatchability rates were $31 \%, 12.5 \%, 10 \%$ for $A n$. gambiae s.s. and Cx. quinquefasciatus $94 \%, 49 \%$ and $34 \%$ in $808.6 ; 1617.2 ; 2625.20$ ppm respectively (Table 4 ). The overall proportions hatched between control and treatments were found to be statistically significant $\left(\chi^{2}=\right.$ 28.98, $P<0.001)$ with less eggs hatching in treatments. The first instars hatched were found dead at the base of the experiments bowls. After 72 hours, no further hatchability of the remained eggs was observed. The hatching rate was considered as the effect of the essential oil concentration due to $100 \%$ hatchability rate in control bowls.

\section{Adult susceptibility test for wild population of $A n$. gambiae s.I}

The one hour mosquito knockdown effect comparison between WHO standard impregnated paper alphacypermethrin $(0.05 \%)$ and the essential oil (1617.20 pmm) impregnated in Whatman filter paper was found to be statistically different $\left(\chi^{2}=18.00, P<0.001\right)$ with a greater knockdown effect on S. terebinthifolia. Alphacypermethrin had $\mathrm{KT}_{50}$ (95\% Confidence Intervals) value of 19.34 (14.21 - 24. 48) while for the essential oil it was found to be 11.29 (10.10 - 12.48). The overall 24 hour mortality was found to be $100.0 \%$ in the essential oil and $85.0 \%$ in alphacypermethrin impregnated papers which was statistically significant $\left(\chi^{2}=14.13, P<0.001\right)$.

\section{Discussion}

The specific gravity of the extracted essential oil was highly significantly lower than the specific gravity previously reported as $0.9097 \pm 0.02$ g. $\mathrm{mL}^{-1}$ [55], and even that of a previous sample of fruits and seeds processed in this same laboratory, that showed a density of 0.8622 $\mathrm{g} \mathrm{mL}^{-1}$ [26]. This was probably because of changes in the quantity and quality of the oil constituents caused by different environmental factors related to soil, sun exposure, amount of water and other external factors. The major compounds found here in the essential oil were the same found by Silva et al.,[26] for fruits and seeds of $S$ terebinthifolia, with slightest differences concerning their percentage composition [26].

One of the first studies with Brazilian pepper essential oil reported that its main constituents were $\alpha$-pinene (12.94\%), $\beta$-pinene (5.02\%), $\alpha$-phellandrene (13.04\%), $\delta$ 3 -carene (29.22\%) and $\beta$-phellandrene (18.08\%) [56]. Another study shows that the major components of this essential oil were $\delta$-3-carene $(30.37 \%)$, limonene (17.44\%), $\alpha$-phellandrene (12.60\%), $\alpha$-pinene (12.59\%), myrcene (5.82\%), and $o$-cymene (3.46\%)[57]. In another study the main constituents were sabinene, $\alpha$-pinene, caryophyllene and germacrene D [58]

These qualitative and quantitative variations in this essential oil composition in a same plant species may be related to several different factors. Sometimes it may happen as a consequence of intra-clonal variation in genetic improvement of exclusively vegetative propagated cultivars of rose-scented geranium, Pelargonium sp., indicating that even somatic genetics may affect the essential oil biosynthesis and production [59]. In other situations, 
Table 2 Overall percentage mortality response of both Anopheles gambiae ss and Culex quinquefasciatus exposed in different concentrations (ppm) of S. terebinthifolia in both laboratory and semi field environments for $\mathbf{7 2}$ hours

\begin{tabular}{|c|c|c|c|c|c|c|}
\hline \multirow[t]{2}{*}{ Study site } & \multirow[t]{2}{*}{ Mosquito species } & \multicolumn{5}{|c|}{ Larval mortality ( $\%$ mean mortality $\pm \mathrm{SE}$ ) } \\
\hline & & 202.15 ppm & $404.30 \mathrm{ppm}$ & $808.60 \mathrm{ppm}$ & 1617.20 ppm & 2625.20 ppm \\
\hline \multirow[t]{2}{*}{ Laboratory } & An. gambiae ss & $13.75 \pm 1.20$ & $20.5 \pm 1.61$ & $92.91 \pm 0.95$ & $93.13 \pm 0.96$ & $97.91 \pm 0.27$ \\
\hline & Cx. quinquefasciatus & $0.5 \pm 0.06$ & $1.25 \pm 0.15$ & $74.37 \pm 2.24$ & $82.50 \pm 1.89$ & $96.75 \pm 0.40$ \\
\hline Chi-square test & & $\chi^{2}=11.34, P<0.001$ & $\chi^{2}=17.18, P<0.001$ & $\chi^{2}=11.24, P<0.001$ & $\chi^{2}=4.33, P=0.047$ & $\chi^{2}=0.005, P=0.862$ \\
\hline \multirow[t]{2}{*}{ Semi field } & An. gambiae ss & $44.13 \pm 0.97$ & $51.96 \pm 1.08$ & $62.61 \pm 1.01$ & $81.03 \pm 1.00$ & $90.64 \pm 0.79$ \\
\hline & Cx. quinquefasciatus & $30.78 \pm 0.81$ & $38.42 \pm 0.96$ & $50.88 \pm 1.05$ & $76.37 \pm 1.21$ & $89.54 \pm 0.89$ \\
\hline Chi-square test & & $\chi^{2}=3.25, P=0.589$ & $\chi^{2}=3.17, P=0.062$ & $\chi^{2}=2.34, P=0.172$ & $\chi^{2}=0.40, P=0.420$ & $\chi^{2}=0.001, P=0.817$ \\
\hline
\end{tabular}

*Values are mean of five replicates in each dosage

*SE: standard error 
Table 3 Larval mean percentage mortality of An.gambiae ss and Cx. quinquefasciatus in a concentration gradient of the S. terebinthifolia fruits extracts in 12, 24, 48 and 72 hours bioassay

\begin{tabular}{|c|c|c|c|c|c|c|}
\hline \multirow[t]{2}{*}{ Experiments } & \multirow[t]{2}{*}{ Mosquito species } & \multirow{2}{*}{$\begin{array}{c}\text { Concentration } \\
(\mathrm{ppm})\end{array}$} & \multicolumn{4}{|c|}{ Larval mortality $\%$ (mean $\pm \mathrm{SE})$} \\
\hline & & & 12 hours & 24 hours & 48 hours & 72 hours \\
\hline \multirow[t]{14}{*}{ Laboratory } & An. gambiae ss & Control & $0.00 \pm 0.00$ & $0.00 \pm 0.00$ & $0.00 \pm 0.00$ & $0.00 \pm 0.00$ \\
\hline & & Control blank & $0.00 \pm 0.00$ & $0.00 \pm 0.00$ & $4.00 \pm 0.28$ & $4.00 \pm 0.28$ \\
\hline & & 202.15 & $0.00 \pm 0.00$ & $12.00 \pm 0.60$ & $21.50 \pm 0.70$ & $29.00 \pm 0.20$ \\
\hline & & 404.30 & $0.00 \pm 0.00$ & $13.50 \pm 0.70$ & $23.50 \pm 0.70$ & $36.50 \pm 0.30$ \\
\hline & & 808.60 & $71.70 \pm 1.00$ & $100.00 \pm 0.00$ & $100.00 \pm 0.00$ & $100.00 \pm 0.00$ \\
\hline & & 1617.20 & $72.50 \pm 1.83$ & $100.00 \pm 0.00$ & $100.00 \pm 0.00$ & $100.00 \pm 0.00$ \\
\hline & & 2625.20 & $91.70 \pm 0.17$ & $100.00 \pm 0.00$ & $100.00 \pm 0.00$ & $100.00 \pm 0.00$ \\
\hline & $C x$ & Control & $0.00 \pm 0.00$ & $0.00 \pm 0.00$ & $0.00 \pm 0.00$ & $0.00 \pm 0.00$ \\
\hline & quinquefasciatus & Control blank & $0.00 \pm 0.00$ & $0.00 \pm 0.00$ & $3.00 \pm 3.00$ & $3.00 \pm 3.00$ \\
\hline & & 202.15 & $0.00 \pm 0.00$ & $3.00 \pm 0.40$ & $5.00 \pm 1.00$ & $5.50 \pm 0.90$ \\
\hline & & 404.30 & $0.00 \pm 0.00$ & $0.00 \pm 0.00$ & $2.00 \pm 0.01$ & $100.00 \pm 0.00$ \\
\hline & & 808.60 & $27.50 \pm 0.50$ & $70.50 \pm 0.10$ & $99.50 \pm 0.10$ & $100.00 \pm 0.00$ \\
\hline & & 1617.20 & $42.50 \pm 3.10$ & $87.50 \pm 1.30$ & $100.00 \pm 0.00$ & $100.00 \pm 0.00$ \\
\hline & & 2625.20 & $87.50 \pm 0.10$ & $99.50 \pm 0.10$ & $100.00 \pm 0.00$ & $100.00 \pm 0.00$ \\
\hline \multirow[t]{14}{*}{ Semi field } & An. gambiae ss & Control & $0.00 \pm 0.00$ & $0.00 \pm 0.00$ & $0.00 \pm 0.00$ & $0.00 \pm 0.00$ \\
\hline & & Control blank & $0.00 \pm 0.00$ & $0.00 \pm 0.00$ & $2.00 \pm 2.00$ & $2.00 \pm 2.00$ \\
\hline & & 202.15 & $3.80 \pm 0.24$ & $30.30 \pm 0.42$ & $64.00 \pm 0.33$ & $81.00 \pm 0.42$ \\
\hline & & 404.30 & $13.50 \pm 0.13$ & $26.00 \pm 0.33$ & $73.50 \pm 0.37$ & $95.00 \pm 0.52$ \\
\hline & & 808.60 & $26.50 \pm 0.27$ & $37.50 \pm 0.34$ & $87.00 \pm 0.27$ & $100.00 \pm 0.00$ \\
\hline & & 1617.20 & $27.00 \pm 0.29$ & $97.70 \pm 0.08$ & $100.00 \pm 0.00$ & $100.00 \pm 0.00$ \\
\hline & & 2625.20 & $39.40 \pm 0.14$ & $99.20 \pm 0.16$ & $100.00 \pm 0.00$ & $100.00 \pm 0.00$ \\
\hline & $C x$ & Control & $0.00 \pm 0.00$ & $0.00 \pm 0.00$ & $0.00 \pm 0.00$ & $0.00 \pm 0.00$ \\
\hline & quinquefasciatus & Control blank & $0.00 \pm 0.00$ & $0.00 \pm 0.00$ & $0.00 \pm 0.00$ & $0.00 \pm 0.00$ \\
\hline & & 202.15 & $2.80 \pm 0.22$ & $19.00 \pm 0.36$ & $34.50 \pm 0.38$ & $70.00 \pm 0.42$ \\
\hline & & 404.30 & $5.70 \pm 0.19$ & $21.00 \pm 0.25$ & $44.00 \pm 0.47$ & $84.50 \pm 0.31$ \\
\hline & & 808.60 & $11.80 \pm 0.18$ & $34.50 \pm 0.31$ & $58.00 \pm 0.31$ & $100.00 \pm 0.00$ \\
\hline & & 1617.20 & $11.00 \pm 0.25$ & $97.70 \pm 0.11$ & $97.80 \pm 0.06$ & $100.00 \pm 0.00$ \\
\hline & & 2625.20 & $31.90 \pm 0.22$ & $100.00 \pm 0.00$ & $100.00 \pm 0.00$ & $100.00 \pm 0.00$ \\
\hline
\end{tabular}

*Values are mean of five replicates in each dosage

*SE: Standard error

those differences may be due to environmental factors that may involve geographical origin, or as a consequence of stress produced by abiotic factors such as wind, and air humidity and salinity [60]. The method of cultivation may also affect variations in essential oil composition
[61], but even the extraction process must not be disregarded [62].

In this case, the experimental extraction process may be rebutted as a cause for this variation, since the three major compounds were the same that were formerly

Table 4 Hatchability hindrance activity of $S$

\begin{tabular}{llll}
\hline $\begin{array}{l}\text { Concentration } \\
\text { (in ppm) }\end{array}$ & Mosquito species & Percentage Ovicidal \pm SE & Chi-square tests \\
\hline 808.60 & An. gambiae ss & $31.00 \pm 1.77$ & $\chi^{2}=82.01, P<0.001$ \\
\hline 1617.20 & Cx. quinquefasciatus & $94.00 \pm 5.37$ & $\chi^{2}=30.29, P<0.001$ \\
\hline $\mathbf{2 6 2 5 . 2 0}$ & An. gambiae ss & $12.50 \pm 1.43$ & $\chi^{2}=14.94, P<0.001$ \\
& Cx. quinquefasciatus & $49.50 \pm 5.66$ & \\
\hline
\end{tabular}

* Values are mean of five replicates for each species in each dosage 
found, in near the same concentrations, after extraction and chromatographic analysis under exactly in the same conditions [26]. Also, although sourced from the same geographical region, the fruits and seeds were collected at the end of fruiting season. So, those slightest quantitative differences in the major compounds, and the qualitative and quantitative differences on minor compounds [26] could potentially be a consequence of seasonality [63].

The screening of products from this essential oil for ovicidal, larvicidal and adulticidal against mosquitoes might lead to innovative compounds for effective use in the abatement and residual application practice against mosquitoes. The widespread use of synthetic organic insecticides for disease vector control has resulted in an increase of resistance selection pressure in the major disease vector species [3]. This has necessitated the search and development of environmentally safe, biodegradable, low-cost, and indigenous methods for vector control, which can be used without risk of harm to individuals and communities $[36,37,54,64]$. The control of mosquitoborne diseases can be achieved either by killing, preventing mosquitoes from biting human beings, or by effective usefulness in the abatement and residual application practices in the environment. S. terebinthifolia essential oil had found to have no effect on non-targeted organisms as also shown by previous studies [26].

In this study, the laboratory and semi-field findings showed highest efficacy in mortality at lower dosages for the $A n$. gambiae s.s. and Cx. quinquefasciatus larvae (Table 2 and Table 3). In ovicidal assessment of An. gambiae s.s. eggs; hatchability was found to be reduced as the concentration increased, larvae hatched in treated experiments were found dead. In the laboratory, mortality was dosage dependent, while in the semi- field, where other variables such as wind and sunlight where present, the lower dosages had impact on larval mortality which was greater than the effect observed within laboratory experiments (Table 2 and 3). The higher mortality in the lower dosages in the semi- field might be attributed to the degradation of compounds due to exposure to sunlight hence inducing more toxicity. The exposure of plant extracts to sunlight causes molecules to degrade to secondary metabolites which are thought to be the causes of this higher mortalities in semi- field experiments with lower $\mathrm{LC}_{50}[65]$.

In assessing the adulticidal effect of S. terebinthifolia essential oil, using semi- gravid females from a wild population of $A n$. gambiae s.l, the time required to knock down $50 \%$ of the $A n$. gambiae s.l was found to be 6.70 minutes while for the standard WHO recommended paper (alphacypermethrin, 0.05\%) it was found to be 27.71 minutes. The $\mathrm{KT}_{50}$ attained by this essential oil was more effective than in previous studies conducted using Ocimum suave plant extracts [37].
In lower Moshi rice irrigation schemes mosquito populations have been reported to have reduced pyrethroid mortalities due to resistance selection pressure in public health- used pyrethroids [5,24]. In different parts of Africa, pyrethroid insecticides resistance has been observed in adult mosquitoes [3-5] and larvae [66], but the efficacy shown in larvae and adult mortality have proved the ability of the $S$. terebinthifolia essential oil to be formulated and incorporated in control strategies in the community for both larvae and adults. The efficacy shown by $S$. terebinthifolia for knockdown time and $100 \%$ mortality after 24 hours to adult mosquitoes from wild resistant population warrants further investigation of these compounds for IRS small scale whether singly or in blends.

This essential oil may be of great value in complementing other compounds which are losing efficacy [67]. From other studies, some phytochemicals have acted as general toxicants against adult as well as larval stages of mosquitoes, while others interfere with growth and development (growth inhibitors) or with reproduction (chemosterilent) or produce olfactory stimuli acting as repellent or attractant [68]. From the last decade, more emphasis has been addressed in larval control for malaria and filarial vector elimination [11-13,16] and control impact has been observed in other areas $[11,12]$. This is because larval habitat treatment is more localized in time and space resulting in effective control. In tropical countries, plants are known to possess larvicidal, ovicidal and adulticidal activities [34,36-38,69].

The results of our present study in ovicidal, larvicidal and adulticidal properties of the essential oil of fruits and seeds of S. terebinthifolia have created the necessity of investigating in detail the ovicidal, larvicidal and adulticidal activities of each chemical compound in this plant extract. In previous studies with S. terebinthifolia, Silva et al. [26] found high mortality in Stegomyia aegypti larvae but no chemical structure was clearly related to these activities shown by fruit extracts.

Further detailed study on the isolated active ingredients responsible for the mosquitocidal activity from these plant fruits may pave the way for the development of an environmentally safe botanical insecticide for the control of mosquitoes at different stages of their life cycle.

\section{Conclusion}

S. terebinthifolia offers potential findings against $A n$. gambiae s.s., An. arabiensis and Cx. quinquefasciatus in its marked ovicidal, larvicidal and adulticidal effects. Results of the effect on non- target organisms have revealed that this plant essential oil is safe to certain nontarget organisms present in the mosquito habitat. However, further studies of the active ingredients involved 
and their mode of action are needed to recommend S. terebinthifolia essential oil before it can be endorsed as an anti- mosquito product that can be used to combat and protect from mosquitoes and integrated in vector control programmes. Further experiments on sub- lethal dosage exposure of mosquito larvae are ongoing to ascertain the possibility of forming resistant mosquitoes.

\section{Acknowledgements}

The authors of this report would like to acknowledge the FUNADESP, for the Research Grant to Ary G. da Silva; the Centro Universitário Vila Velha - UW, and the laboratories Tommasi Analitica and Tommasi Laboratório for technological support for the microbiological and chromatographic analyses, respectively. Thanks to Violet Temba, Jemima Hamisi and Ester Lyatuu for their assistance in laboratory and semi field experiments. Further thanks to Mr. Augustino Mtui and Charles Massenga for field experiments conducted in lower Moshi Northern Tanzania.

\section{Author details}

${ }^{1}$ Tropical Pesticides Research Institute, Division of Livestock and Human Disease Vectors Control, Mosquitoes Section, P.O.Box 3024, Arusha, Tanzania. ${ }^{2}$ Kilimanjaro Christian Medical College, Tumaini University, P.O.Box 2240, Moshi, Tanzania. ${ }^{3}$ Centro Universitário Vila Velha - UW. Rua Comissário José Dantas de Melo, 21, Boa Vista, Vila Velha, ES, CEP 29.102-770, Brazil. ${ }^{4}$ Tommasi Analítica. Avenida Luciano das Neves, 2016, Divino Espírito Santo, Vila Velha, ES, CEP. 29.107-010, Brazil.

\section{Authors' contributions}

EJK and AGS conceived and designed the study, as well as carrying out the statistical data analyses. AGS carried out the extraction, purification, physicalchemical, and chemical analysis of essential oil, and microbiological bioassays. EJK wrote the manuscript. EJK, AGS, MN and FM revised the manuscript. All authors read and approved this final version.

\section{Competing interests}

The authors declare that they have no competing interests.

Received: 15 May 2011 Accepted: 5 July 2011 Published: 5 July 2011

\section{References}

1. Ministry of Health: National Malaria Medium-term Strategic Plan, July 2002-June 2006. Dar Es Salaam, Tanzania; 2002.

2. Ministry of Health and Social Welfare: National malaria control medium term malaria strategic plan, February 2008 - January 2013. Dar Es Salaam, Tanzania; 2008.

3. Baleta A: Insecticide resistance threatens malaria control in Africa. Lancet 2009, 374:1581-1582.

4. Carnevale $\mathrm{P}$, Toto JC, Guibert $\mathrm{P}$, Keita M, Manquin S: Entomological survey and report of a knockdown resistance mutation in the malaria vector Anopheles gambiae from the Republic of Guinea. Trans R Soc Trop Med Hyg 2010, 104:484-489.

5. Matowo J, Kulkarni MA, Mosha FW, Oxborough RM, Kitau JA, Tenu F, Rowland M: Biochemical basis of permethrin resistance in Anopheles arabiensis from Lower Moshi, north-eastern Tanzania. Malar J 2010, 9:193.

6. Casimiro S, Coleman M, Hemingway J, Sharp B: Insecticide resistance in Anopheles arabiensis and Anopheles gambiae from Mozambique. J Med Entomol 2006, 43:276-282.

7. Casimiro S, Coleman M, Mohloai P, Hemingway J, Sharp B: Insecticide resistance in Anopheles funestus (Diptera: Culicidae) from Mozambique. $J$ Med Entomol 2006, 43:267-275.

8. Greenwood B, Mutabingwa T: Malaria in 2002. Nature 2002, 415(6872):670-672

9. Pearce RJ, Pota H, Evehe MS, Ba el H, Mombo-Ngoma G, Malisa AL, Ord R, Inojosa W, Matondo A, Diallo DA, et al: Multiple origins and regional dispersal of resistant dhps in African Plasmodium falciparum malaria. PLoS Med 2009, 6:e1000055.

10. White NJ: Artemisinin resistance-the clock is ticking. Lancet 2010, 376:2051-2052.
11. Fillinger $U$, Knols $B G$, Becker $N$ : Efficacy and efficiency of new Bacillus thuringiensis var israelensis and Bacillus sphaericus formulations against Afrotropical anophelines in Western Kenya. Trop Med Int Health 2003, 8:37-47.

12. Fillinger $U$, Lindsay $S W$ : Suppression of exposure to malaria vectors by an order of magnitude using microbial larvicides in rural Kenya. Trop Med Int Health 2006, 11:1629-1642.

13. Fillinger $\mathrm{U}$, Sonye G, Killeen GF, Knols BG, Becker N: The practical importance of permanent and semipermanent habitats for controlling aquatic stages of Anopheles gambiae sensu lato mosquitoes: operational observations from a rural town in western Kenya. Trop Med Int Health 2004, 9:1274-1289.

14. Lengeler C, Sharp B: Indoor residual spraying and insecticide-treated nets. In: Reducing malaria's burden:evidence of effectiveness for decision makers. Global Health Council: 2003 Washington D.C; 2003, 17-24.

15. Majambere S, Fillinger U, Sayer DR, Green C, Lindsay SW: Spatial distribution of mosquito larvae and the potential for targeted larval control in The Gambia. Am J Trop Med Hyg 2008, 79:19-27.

16. Majambere S, Lindsay SW, Green C, Kandeh B, Fillinger U: Microbial larvicides for malaria control in The Gambia. Malar J 2007, 6:76.

17. Zaim M, Aitio A, Nakashima N: Safety of pyrethroid-treated mosquito nets. Med Vet Entomol 2000, 14:1-5.

18. Dye TD, Apondi R, Lugada ES, Kahn JG, Smith J, Othoro C: "Before we used to get sick all the time": perceptions of malaria and use of long-lasting insecticide-treated bed nets (LLINs) in a rural Kenyan community. Malar J 2010, 9:345.

19. Chandre F, Darriet F, Doannio JM, Riviere F, Pasteur N, Guillet P: Distribution of organophosphate and carbamate resistance in Culex pipiens quinquefasciatus (Diptera: Culicidae) in West Africa. J Med Entomol 1997, 34:664-671.

20. N'Guessan R, Darriet F, Guillet P, Carnevale P, Traore-Lamizana M, Corbel V, Koffi AA, Chandre F: Resistance to carbosulfan in Anopheles gambiae from Ivory Coast, based on reduced sensitivity of acetylcholinesterase. Med Vet Entomol 2003, 17:19-25.

21. Georghiou GP, Metcalf RL, Gidden FE: Carbamate-resistance in mosquitos. Selection of Culex pipiens fatigans Wiedemann (C. quinquefasciatus Say) for resistance to Baygon. Bull World Health Organ 1966, 35:691-708.

22. Djogbenou L, Pasteur N, Akogbeto M, Weill M, Chandre F: Insecticide resistance in the Anopheles gambiae complex in Benin: a nationwide survey. Med Vet Entomol 2010.

23. Tren R, Roberts D: DDT and malaria prevention. Environ Health Perspect 2010, 118: 14-15.

24. Mosha FW, Lyimo IN, Oxborough RM, Malima R, Tenu F, Matowo J, Feston E, Mndeme R, Magesa SM, Rowland M: Experimental hut evaluation of the pyrrole insecticide chlorfenapyr on bed nets for the control of Anopheles arabiensis and Culex quinquefasciatus. Trop Med Int Health 2008, 13:644-652.

25. Bernadou A, Demares F, Couret-Fauvel T, Sandoz JC, Gauthier M: Effect of fipronil on side-specific antennal tactile learning in the honeybee. $J$ Insect Physiol 2009, 55:1099-1106.

26. Silva AG, Almeida DL, Ronchi SN, Bento AC, Scherer R, Ramos AC, Cruz ZM: The essential oil of Brazilian pepper, Schinus terebinthifolia Raddi in larval control of Stegomyia aegypti (Linnaeus, 1762). Parasit vectors 2010, 3:79.

27. Chase C, Sicuri E, Sacoor C, Nhalungo D, Nhacolo A, Alonso PL, Menendez C: Determinants of household demand for bed nets in a rural area of southern Mozambique. Malar J 2009, 8:132.

28. Somi MF, Butler JR, Vahid F, Njau JD, Kachur SP, Abdulla S: Economic burden of malaria in rural Tanzania: variations by socioeconomic status and season. Trop Med Int Health 2007, 12:1139-1147.

29. Chogo JBA, Crank G: Chemical composition and biological activity of the Tanzania plant Ocimum suave. J Nat Prod 1981, 44:308-309.

30. Zahir AA, Rahuman AA, Kamaraj C, Bagavan A, Elango G, Sangaran A, Kumar BS: Laboratory determination of efficacy of indigenous plant extracts for parasites control. Parasitol Res 2009, 105:453-461.

31. Cetin H, Cilek JE, Aydin L, Yanikoglu A: Acaricidal effects of the essential oil of Origanum minutiflorum (Lamiaceae) against Rhipicephalus turanicus (Acari: Ixodidae). Vet Parasitol 2009, 160:359-361.

32. Trudel RE, Bomblies A: Larvicidal effects of Chinaberry (Melia azederach) powder on Anopheles arabiensis in Ethiopia. Parasit vectors 2010, 4:72. 
33. Innocent E, Joseph CC, Gikonyo NK, Nkunya MH, Hassanali A: Constituents of the essential oil of Suregada zanzibariensis leaves are repellent to the mosquito, Anopheles gambiae s.s. J Insect Sci 2010, 10:57.

34. Kihampa C, Joseph CC, Nkunya MH, Magesa SM, Hassanali A, Heydenreich M, Kleinpeter E: Larvicidal and IGR activity of extract of Tanzanian plants against malaria vector mosquitoes. J Vector Borne Dis 2009, 46:145-152.

35. Kweka EJ, Lyatuu EE, Mboya MA, Mwang'onde BJ, Mahande AM: Oviposition Deterrence Induced by Ocimum kilimandscharicum and Ocimum suave Extracts to Gravid Anopheles gambiae s.s (Diptera: Culicidae) in Laboratory. J Glob Infect Dis 2010, 2:242-245.

36. Kweka EJ, Mosha F, Lowassa A, Mahande AM, Kitau J, Matowo J, Mahande MJ, Massenga CP, Tenu F, Feston E, Lyatuu EE, Mboya MA Mndeme R, Chuwa G, Temu EA: Ethnobotanical study of some of mosquito repellent plants in north-eastern Tanzania. Malar J 2008, 7:152.

37. Kweka EJ, Mosha FW, Lowassa A, Mahande AM, Mahande MJ, Massenga CP Tenu F, Lyatuu EE, Mboya MA, Temu EA: Longitudinal evaluation of Ocimum and other plants effects on the feeding behavioral response of mosquitoes (Diptera: Culicidae) in the field in Tanzania. Parasit vectors 2008, 1:42.

38. Trudel RE, Bomblies A: Larvicidal effects of Chinaberry (Melia azederach) powder on Anopheles arabiensis in Ethiopia. Parasit vectors 2011, 4:72.

39. Lenzi M, Orth Al: Fenologia reprodutiva, morfologia e biologia floral de Schinus terebinthifolius Raddi (Anacardiaceae), em restinga da llha de Santa Catarina, Brasil. Biotemas 2004, 17:67-89.

40. Degáspari $\mathrm{CL}$, Waszczynskyj N: Propriedades antimicrobianas dos frutos da aroeira (Schinus terebenthifolius Raddi). Ciência e Agrotecnologia 2005, 29:617-622.

41. Pires OC, Taquemasa AVC, Akisue G, Oliveira F, Araújo CEP: Preliminary comparative analysis of the acute toxicity and median lethal dose of the fruit of the Brazilian black pepper (Schinus terebinthifolius Raddi) and black pepper (Piper nigrum L.). Latin Am J Pharm 2004, 23:176-182.

42. Santos LC, Amorim MMR: Uso da aroeira (Schinus terebinthifolius Raddi) para tratamento de infecções vaginais. Femina 2002, 30:339-420.

43. Mourelle J: Anti-inflammatory activity of Schinus terebinthifoluis (Copal) in rats. Rev Cuba Farm 1993, 27:139-144.

44. Jain MK, Yu BZ, Rogers JM, Smith AE, Boger ET, Ostrander RL, Rheingold AL: Specific competitive inhibitor of secreted phospholipase A2 from berries of Schinus terebinthifolius. Phytochemistry 1995, 39:537-547.

45. Martinez MJ, Betancourt J, Alonso-Gonzalez N, Jauregui A: Screening of some Cuban medicinal plants for antimicrobial activity. J Ethnopharmacol 1996, 5:171-174.

46. Siddiqui R, Zunino MP, JA Z: Tagetes minuta and Schinus areira essential oils as allelopathic agents. Biochem Syst Ecol 2003, 31:563-572.

47. Prakash A, Rao J: Botanical pesticides in agriculture. Lewis: Boca Raton; 1997.

48. Finch S: Assessing host-plant finding by insects. In Insect-plant interactions. Edited by: Mille JR, Miller TA. New York: Springer-Verlag; 1986:23-63.

49. Adams RP: Identification of essential oil components by gas chromatography/mass spectrometry.Edited by: Stream C. Allured Publishing Corporation; 2009:

50. World Health Organisation: Guidelines for laboratory and field testing of mosquito larvicides. WHO/CDS/WHOPES/GCPP/2005 2005

51. Knols BG, Njiru BN, Mathenge EM, Mukabana WR, Beier JC, Killeen GF: MalariaSphere: a greenhouse-enclosed simulation of a natural Anopheles gambiae (Diptera: Culicidae) ecosystem in western Kenya. Malar J 2002, 1:19.

52. World Health Organisation: Manual on practical entomology in malaria. Part II.Methods and Techniques. Division of Malaria and Other Parasitic Diseases Geneva; 1975.

53. World Health Organisation: Test Procedures for insecticide resistance monitoring in malaria vectors, bio-efficacy and persistence of insecticides on treated surfaces. Report of the WHO Informal Consultation. Document WHO/CDS/CPC/MAL/1998.12. Geneva: World Health Organization; 1998, 1-43.

54. Abbott WS: A method of computing the effectiveness of an insecticide. $J$ Med Entomol 1925, 18:265-266

55. Cole E: Estudo fitoquímico do óleo essencial dos frutos da aroeira (Schinus terebinthifolius Raddi) e sua eficácia no combate ao dengue. MSc dissertation Federal University of the Espírito Santo - Brazil; 2008.
56. Clemente AD: Estudo fitoquímico do óleo essencial dos frutos da aroeira (Schinus terebinthifolius Raddi) e sua eficácia no combate ao dengue. MSc dissertation MG - Brazil: Federal University of the Viçosa; 2006.

57. Cole ER: Estudo fitoquímico do óleo essencial dos frutos da aroeira (Schinus terebinthifolius Raddi) e sua eficácia no combate ao dengue. MSc dissertation Federal University of the Espírito Santo - Brazil; 2008.

58. Santos ACA, Rossato M, Agostini F, Dos Santos PL, Serafini LA, Moyna P, Dellacassa E: Avaliação química mensal de três exemplares de Schinus terebinthifolius Raddi. Rev Bras Biociências 2007, 5:1011-1013.

59. Kulkarni RN, Baskaran K, Ramesh S, Kumar S: Intra-clonal variation for essential oil content and composition in plants derived from leaf cuttings of rose-scented geranium (Pelargonium sp.). Ind Crops Prod 1997, 6:107-112

60. Kokkini S, Karousou R, DV: Pattern of geographic variation of Origanum vulgare trichomes and essential oil content in Greece. Biochem Sys Ecol 1994, 22:517-528.

61. Paul A, Thapaa G, Basub A, Mazumdarb P, Kalita MC, Sahoo L: Rapid plant regeneration, analysis of genetic fidelity and essential aromatic oil content of micropropagated plants of Patchouli, Pogostemon cablin (Blanco) Benth. - an industrially important aromatic plant. Ind Crops Prod 2010, 32:366-374.

62. Sefidkon F, Abbasi K, Jamzad Z, Ahmadi S: The effect of distillation methods and stage of plant growth on the essential oil content and composition of Satureja rechingeri Jamzad. Food Chem 2007, 100:1054-1058.

63. Paolini J, Barboni T, Desjobert JM, Djabou N, Muselli A, Costa J: Chemical composition, intraspecies variation and seasonal variation in essential oils of Calendula arvensis L. Biochem Sys Ecol 2010, 38:865-874.

64. Mittal PK, Adak T, Batra CP: Comparative toxicity of selected larvicidal formulations against Anopheles stephensi Liston and Aedes aegypti Linn. J Commun Dis 2001, 33:116-120.

65. Arfsten DP, Schaeffer DJ, Mulveny DC: The effects of near ultraviolet radiation on the toxic effects of polycyclic aromatic hydrocarbons in animals and plants: a review. Ecotoxicol environ safety 1996, 33:1-24.

66. French $W L$, Kitzmiller JB: Time in concentration: a simple technique for the accurate detection of resistance to insecticides in mosquito larvae. Bull World Health Organ 1965, 32:133-142.

67. Tren R, Roberts D: DDT and malaria prevention. Environ Health Perspect 2010, 118:A14-15.

68. Ghosh A, Chowdhury N, Chandra G: Laboratory evaluation of a phytosteroid compound of mature leaves of Day Jasmine (Solanaceae: Solanales) against larvae of Culex quinquefasciatus (Diptera: Culicidae) and nontarget organisms. Parasitol Res 2008, 103:271-277.

69. Nkunya MH, Jonker SA, de Gelder R, Wachira SW, Kihampa C: (+/-)-Schefflone: a trimeric monoterpenoid from the root bark of Uvaria scheffleri. Phytochemistry 2004, 65:399-404.

doi:10.1186/1756-3305-4-129

Cite this article as: Kweka et al:: Insecticidal activity of the essential oil from fruits and seeds of Schinus terebinthifolia Raddi against African malaria vectors. Parasites \& Vectors 2011 4:129.

\section{Submit your next manuscript to BioMed Central and take full advantage of:}

- Convenient online submission

- Thorough peer review

- No space constraints or color figure charges

- Immediate publication on acceptance

- Inclusion in PubMed, CAS, Scopus and Google Scholar

- Research which is freely available for redistribution

Submit your manuscript at www.biomedcentral.com/submit
C Biomed Central 